\title{
CHEMICAL AND PHYSICAL PREPARATION OF ACTIVATED CARBON USING RAW BAGASSE PITH FOR CATIONIC DYE ADSORPTION
}

\author{
TAHA N.A. ${ }^{1,2, *}$, \\ ABDELHAFEZ S.E. ${ }^{2,3}$ \\ EL-MAGHRABY A. ${ }^{2}$
}

\author{
${ }^{1}$ Chemistry Department, Al-Lith University College \\ Umm Al-Qura University, Saudi Arabia \\ ${ }^{2}$ Department of Fabrication Technology \\ Advanced technology and New Materials Research Institute \\ City for Scientific Research and Technology Applications \\ Alexandria, Egypt. \\ ${ }^{3}$ Chemical and Petrochemicals Engineering Department \\ Egypt-Japan University of Science and Technology \\ New Borg El-Arab City, Alexandria, Egypt
}

Received: 02/02/2016

Accepted: 04/05/2016

Available online: 16/05/2016 *to whom all correspondence should be addressed: e-mail: nahlataha_1982@yahoo.com

\section{ABSTRACT}

Agriculture wastes like sugarcane bagasse are available in large quantities in Egypt. Various adsorbents from natural materials, industrial waste materials, agricultural by-products, and biomass based activated carbon can be used in the removal of various dyes. Raw Bagasse pith (RBP) was used to prepare activated carbon (AC) using phosphoric acid $\left(\mathrm{H}_{3} \mathrm{PO}_{4}\right)$ as a chemical activating agent. $\mathrm{C}$ The raw BP and the synthesized adsorbent were characterized by Fourier transform infrared (FTIR) spectroscopy and scanning electron microscope (SEM). The effectiveness of AC prepared in adsorption of methylene blue (MB) has been studied as a function of adsorbent type, initial dye concentration and contact time. The effects of the initial dye concentration and contact time were evaluated. Adsorption isotherm models - Langmuir, Freundlich and Temkin were used to simulate the equilibrium data. Langmuir equation was found to have the highest value of $R^{2}$ compared with other models. Furthermore, it was found that sugarcane bagasse have a high adsorptive capacity towards MB.

Keywords: activated carbon, agriculture waste, cationic dye

\section{Introduction}

Dye production industries and many others industries which used dyes and pigments generate, characteristically high in colour and organic content. About 10,000 different commercial dyes and pigments exist and over $7 \times 10^{5}$ tones are produced annually worldwide (Gong et al., 2005). In textile dyeing processes, a large volume of dye contaminated effluent is discharged and it is estimated that $10-15 \%$ of the dye is lost in the dye effluent. The effluents of these industries are highly colored and the disposal of these wastes into receiving water causes damage to the environment as they may significantly affect photosynthetic activity in aquatic life due to reduced light penetration and may also be toxic to some aquatic life due to the presence of metals, chlorides, etc.(Zollinger, 1987). Dyes are synthetic organic compounds with a chemical complex

Taha N.A., Abdelhafez S.E. and El-Maghraby A. (2016), Chemical and physical preparation of activated carbon using raw bagasse pith for cationic dye adsorption, Global NEST Journal, 18(2), 402-415. 
structure that are stable to light, heat, oxidizing agents and resistant to aerobic digestion (Crini, 2006; Wu et al., 2008). The wastewater generated by the processes of dyes industries like tannery, textiles, paper and plastics usually contains up to around $10 \%$ of used dye (Forgacs et al., 2004). Dyes are stable in the receiving environment and posing a serious threat to human and environmental health (Crini, 2008). One of the most famous cationic dyes is methylene Blue (MB). $\mathrm{MB}$ is a heterocyclic aromatic chemical compound with a molecular formula of $\mathrm{C}_{16} \mathrm{H}_{18} \mathrm{~N}_{3} \mathrm{ClS}$. It has the favorable characteristics of bright color and simple application techniques. $\mathrm{MB}$ is used extensively in dying natural fibers such as cotton and silk. It can cause eye burns by direct contact and nausea, vomiting, profuse sweating, mental confusion and methemoglobinemia by ingestion (Gusmãoa et al., 2012). Accordingly, to protect humans and the receiving ecosystem from contamination, the dyes must be removed from the wastewater before being released into the environment. Various methods of dye removal including aerobic and anaerobic microbial degradation, coagulation, chemical oxidation, membrane separation, electrochemical treatment, filtration, flotation, hydrogen peroxide catalysis, and reverse osmosis have been proposed from time to time. Municipal aerobic treatment systems were found to be ineffective in the removal of dyes because dye molecules are resistant to biodegradation (Lazaridis et al., 2003; Moussavi et al., 2011). Different chemical advanced oxidation processes have been shown to be efficient for the degradation of several classes of dyes but they are expensive and economically non-attractive. Adsorption is one of the most efficient methods and the main adsorbent used for this purpose is activated carbon due to its excellent adsorption capability (Moussavi et al., 2011). However, the production of activated carbon is complex and expensive, making this technology nonefficient. Accordingly, a critical challenge is finding a low-cost adsorbent that is locally available with high removal capacity so adsorption can successfully compete with other dye removal techniques (Rachakornkij et al., 2004).

The sorption of dye onto agricultural by-products is becoming a potential alternative for inorganic/organic removal from aqueous solution. It is economic, environmental friendly, efficient for dye removal and is able to replace the most widely used commercial activated carbon. Waste materials and raw agricultural solid wastes from forest industries such as bark and sawdust have been applied as adsorbents for dye removal. Agricultural by-products are available in large quantities around the world, as wastes (Foo et al., 2011).

Natural material like wood, peat, agricultural waste and by-product such as shells of almond and hazelnut, sawdust corncob, rice husk and sugarcane bagasse have been studied to adsorb synthetics dyes. The native exchange capacity and general sorption characteristics of these materials derive from their constituents, which contain a variety of functional groups that can adsorb certain contaminants in water (Tseng, 2002). Agricultural waste materials are abundant and have been proven to be good low cost adsorbents due to their easy conversion to a value-added product. These materials have been used as adsorbent without any chemical modification. In addition, the chemical modification can introduce functionality to these solid supports, increasing their adsorption capacity and efficiency (Devaprasath et al., 2007; Miretsky et al., 2010). Sugarcane bagasse is an excellent solid support because it is inexpensive in comparison to other solid support, high efficiency and easy to obtain. Beside, owing to the increase of bioethanol production bagasse has been burned to produce steam and energy for the process: nevertheless, this residue produces ecological problems due to its low natural degradation rate and because it is commonly eliminated by burning, thereby becoming a source of atmospheric pollution. These results have encouraged us to continue exploring the potential of a BP to remove contaminants from water such as dyes that are usually found in wastewater (Litza et al., 2013). The composition of sugarcane bagasse is $40-50 \%$ cellulose, $25-30 \%$ hemicelluloses, and $20-25 \%$ lignin (Gusmãoa et al., 2012).

Activated carbon is the most popular for the removal of pollutants from wastewater among all the sorbent materials proposed (Ramakrishna et al., 1997; Babel et al., 2003). In particular, the effectiveness of adsorption on activated carbons for removal of a large variety of dyes from wastewaters has made it an ideal alternative to other expensive treatment options (Ramakrishna et al., 1997). 
The main purpose of the present study was to explore the capability of activated carbon from raw BP to remove a basic model dye, $M B$, from liquid media under different experimental conditions. Effects of main parameters were also studied for MB removal. In this study, three models (Langmuir, Freundlich and Temkin) Annadurai et al., 2002; El-Geundi, 1991; Miah et al., 2010; Annadurai et al., 1999; Zhao et al., 1989) have been used to describe the sorption process of MB onto sugarcane bagasse.

\section{Material and method}

\subsection{Materials}

Bagasse was obtained from a cane mill. Bagasse is an extremely inhomogeneous material comprising around $30-40 \%$ of "pith" fiber (inner fiber) and "stem" fiber (outer layer). In this study the two portions was separated and pith bagasse (BP) was taken as the primary material. Pith bagasse composed mainly of cellulose, lignin, hemicelluloses, wax and ash.

$\mathrm{MB}$ with a molecular formula of $\mathrm{C}_{16} \mathrm{H}_{18} \mathrm{~N}_{3} \mathrm{ClS}$ was purchased from Nice Chemicals Pvt. Ltd. The structure of $\mathrm{MB}$ is shown in Fig. 1. The MB used in the present study has a molecular weight of 319.85 with its maximum absorbance at a wavelength of $655 \mathrm{~nm}$. Pure $\mathrm{H}_{3} \mathrm{PO}_{4}(85 \%)$ aqueous solutions was purchased from Riedel-de Haen.

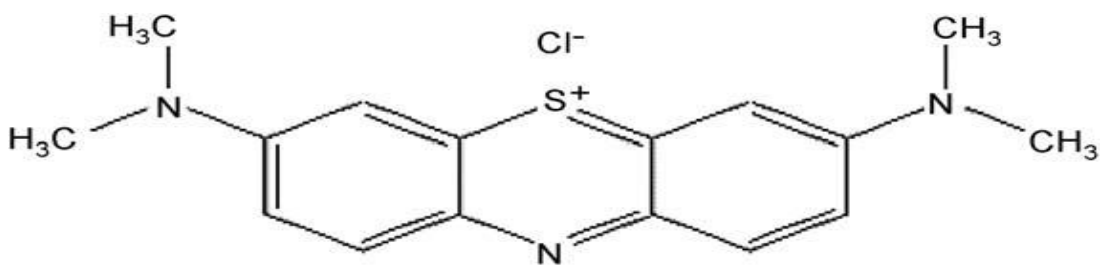

Figure. 1. The structures of methylene blue dye.

\subsection{Preparation of adsorbent material}

(1) Raw bagasse

Firstly pith bagasse was washed thoroughly with tap water to remove dust particles, and then boiled in distilled water for one hour to remove the sugar residue in the bagasse. After that the washed bagasse was filtrated and exposed to sunlight then dried on an oven at $60^{\circ} \mathrm{C}$ until reach to constant weight. Dried bagasse was crushed in a blender and sieved to obtain a uniform grain size. Finally, the sieved material stored in vacuum desiccators for further use and labeled as raw bagasse pith (RBP).

(2) Thermal activation

Activated carbon was prepared from RBP by only applying thermal affect and this achieved by put the sample in steel tube and put this tube in muffle furnace (Barnstead Thermolyne) for carbonization. Carbonization temperature was $600{ }^{\circ} \mathrm{C}$ for $1 \mathrm{hr}$. The carbonized material stored in vacuum desiccators for further use and labeled as physical carbon (PC).

(3) Chemical activation

Activated carbons using RBP was prepared by phosphoric acid. For activation, the RBP was subject to digestion with phosphoric acid by boiling it in $40 \%$ phosphoric acid for one hour (mass ratio of raw bagasse pith to phosphoric acid 1:9.8) by using mechanical stirrer with heater. The mixture was filtrated, washed with distilled water then let it dry in air. Treated material putted in muffle furnace for carbonization. Varying the 
carbonization temperature $\left(400,500,600\right.$ and $\left.700{ }^{\circ} \mathrm{C}\right)$ for 1 hour. The carbonized material stored in vacuum desiccators for further use.

\subsection{Characterization of bagasse pith and activated carbon}

Surface group information of adsorbent was detected using the pressed potassium bromide ( $\mathrm{KBr}$ ) pellets containing 5\% sample by FTIR spectrometer (Shimadzu, FTIR-8400S. Japan) in the scanning range of $4000-$ $400 \mathrm{~cm}^{-1}$. The morphologies were obtained with a scanning electron microscope (JEOL, model JSM-6360 OLA).

\subsection{Preparation of dye solution}

$\mathrm{MB}$ was used to prepare the synthetic wastewater solution. An accurately weighed quantity of MB $(1 \mathrm{~g})$ was dissolved in 1 liter distilled water to prepare the stock solution (1000 ppm). Experimental solutions of the desired concentrations were obtained by successive dilutions. These solutions were then properly wrapped with aluminum foil and stored in a dark place to prevent direct sunlight, which may cause de-composition.

\subsection{Batch experiment}

Sorption experiments were carried out by agitating certain amount of different types of sorbent (RBP, PC and chemical activated carbon at different temperatures) in $50 \mathrm{ml}$ of varying concentration of dye solution (10, 15, 25 and $30 \mathrm{ppm}$ ) in an incubator ( MAXQ 4000 Incubator shaker) at certain speed for $1 \mathrm{~h}$ at room temperature. After that, the mixtures were filtered and the dye concentrations in the supernatant solutions were analyzed using a Spectrophotometer (Ultropec $2000 \mathrm{UV} / \mathrm{visible).} \mathrm{Then} \mathrm{concentrations} \mathrm{of} \mathrm{residual} \mathrm{dye}$ solutions were measured by monitoring the absorbance changes at a wavelength of maximum absorbance $(\lambda$ $=665 \mathrm{~nm}$ ) for MB dye. The amount of dye sorbed at any time, $q_{t}$, was calculated from;

$\mathrm{q}_{\mathrm{t}}=\mathrm{V}\left(\mathrm{C}_{\mathrm{o}}-\mathrm{C}_{\mathrm{t}}\right) / \mathrm{W}$

At equilibrium, $\mathrm{q}_{\mathrm{t}}=\mathrm{q}_{\mathrm{e}}$ and $\mathrm{C}_{\mathrm{t}}=\mathrm{C}_{\mathrm{e}}$; therefore the amount of adsorbed dye, $\mathrm{q}_{\mathrm{e}}$ was calculated from

$\mathrm{q}_{\mathrm{e}}=\mathrm{V}\left(\mathrm{C}_{\mathrm{o}}-\mathrm{C}_{\mathrm{e}}\right) / \mathrm{W}$

where $C_{0}, C_{t}$ and $C_{e}$ are the initial concentration, concentration at any time and equilibrium concentrations of dye solution ( $\mathrm{mg} \mathrm{l}^{-1}$ ), respectively, $\mathrm{V}$ is the volume of the solution (I), and $\mathrm{W}$ is the mass of adsorbent (g) (Devaprasath, 2007). The dye removal percentage can be calculated from this equation,

$\%$ Removal $=\left(C_{0}-C_{t}\right) / C_{o} * 100$

\subsection{Effects of initial dye concentration and contact time}

$\mathrm{MB}$ in water solutions having different concentrations $(10-30 \mathrm{ppm})$ is added with constant dose $0.1 \mathrm{gm}$ of adsorbent respectively for samples. The mixture stirred at $200 \mathrm{rpm}$ and room temperature for different time (5-120 min.), to test the effect of initial concentration and contact time on the adsorption process. It is filtered and colorimetric readings are noted for each solution at equilibrium.

\section{Results and Discussion}

\subsection{Characterization of sugarcane bagasse and its activated carbon}

The textural and chemical properties of bagasse and which resulting from activation of bagasse were characterized. These variables are important in the adsorption properties of these adsorbents. The characteristics of bagasse and its activated carbon were made by FTIR and Scanning electron microscope. 


\subsubsection{Using FTIR spectroscopy}

In order to understand the changes in the chemical structure after pretreatment, infrared spectra (Figure 2) of the untreated and pretreated samples were obtained. The broad band centered at $3392 \mathrm{~cm}^{-1}$ is attributed to symmetric and asymmetric stretching vibrations of $\mathrm{O}-\mathrm{H}$ absorbed water molecules. Also the band observed at $3392 \mathrm{~cm}^{-1}$ is characteristic of $\mathrm{OH}$ groups present in lignin and carbohydrates. The weak band at $2910 \mathrm{~cm}^{-1}$ could be attributed to $\mathrm{C}-\mathrm{H}$ aliphatic axial deformation in $\mathrm{CH}_{2}$ and $\mathrm{CH}_{3}$ groups from cellulose, lignin and hemicelluloses. The relative absorbance of the bands of $\mathrm{OH}$ groups was at $1047 \mathrm{~cm}^{-1}$ (OH stretching). The medium band at $1632 \mathrm{~cm}^{-1}$ is attributed to $\mathrm{C}=\mathrm{C}$ aromatic skeletal vibration. This band is generally found in the lignin aromatic structure. The band at $1702 \mathrm{~cm}^{-1}$ is referred to the acetyl groups present in the hemicelluloses. The peak at $1363 \mathrm{~cm}^{-1}$ is attributed to the vibration of phenolic group. The peak at $1047 \mathrm{~cm}^{-1}$ is corresponded to the $\mathrm{C}-\mathrm{O}-\mathrm{C}$ (ester, ether and phenol). The strong band at $1702 \mathrm{~cm}^{-1}$ in pretreated sugarcane bagasse is assign to $\mathrm{C}-\mathrm{O}$ stretching in cellulose, hemicelluloses and lignin. The weak band at $1253 \mathrm{~cm}^{-1}$ is attributed to the $\mathrm{C}-\mathrm{O}$ stretching of phenol. The strong band at $585 \mathrm{~cm}^{-1}$ is attributed to the $\mathrm{C}-\mathrm{H}$ bend. The results indicated that thermal and acidic treatment causes the degradation of fiber structure of cellulose and lignin to greater extent. Figure 2 shows higher values of relative absorbance in the case of untreated samples as compared to pretreated samples. This result could be attributed to the chemical changes observed when sugar cane bagasse is pretreated with phosphoric acid and heat (Kaur et al., 2013).

The phosphoric acid modified samples have peaks at $\sim 1150 \mathrm{~cm}^{-1}$ and $1000 \mathrm{~cm}^{-1}$ which could be from C-O-P and P-O respectively (Liou, 2010; Puziy et al., 2005).

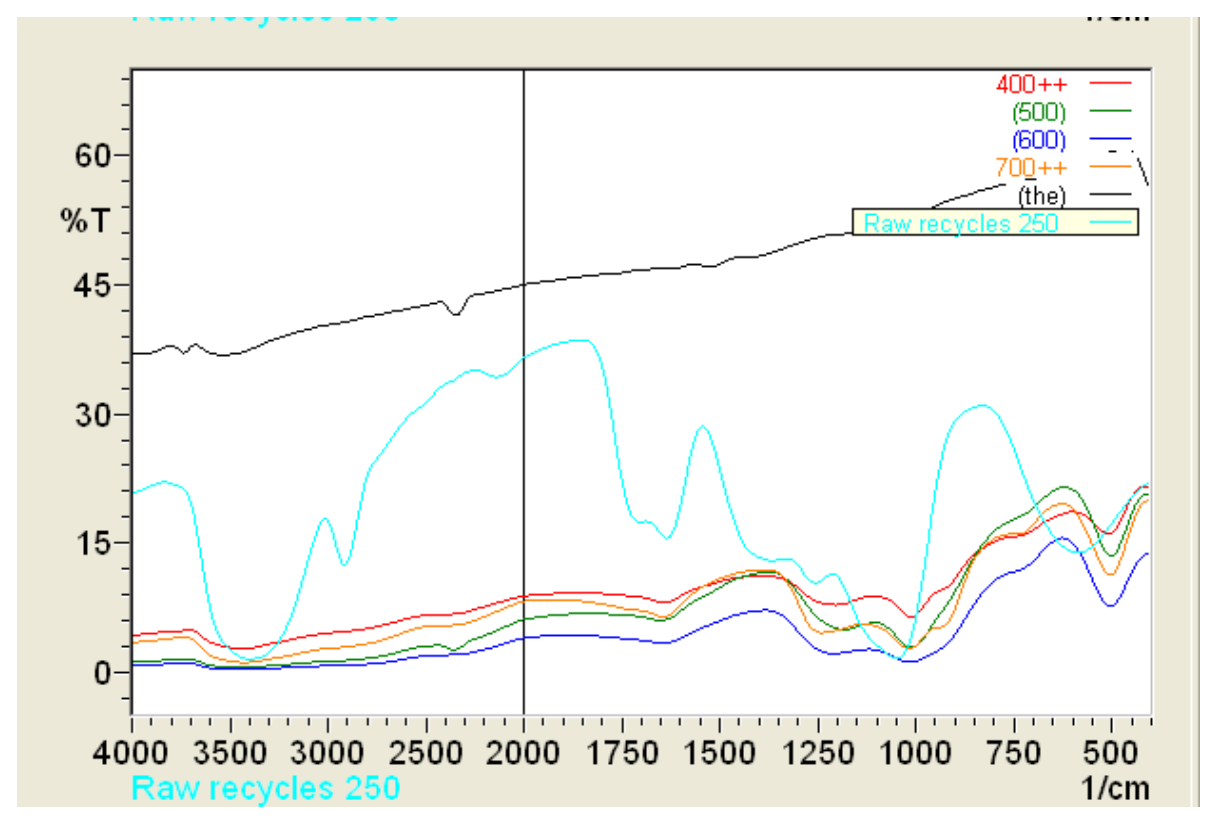

Figure 2. FTIR spectra of modified and unmodified sugarcane bagasse

\subsubsection{Using SEM}

After examination of the SEM micrograph, the presence of heterogeneous and highly porous cavities over the surface of raw sugarcane bagasse were identified. This indicates good possibility for the pollutants to be adsorbed.

Comparison of the micrographs before and after adsorption of MB are shown in Fig. $3(a, b)$ and Fig. $4(a, b)$, respectively. It showed various important changes the adsorption of $\mathrm{MB}$ onto the raw bagasse pith led to the formation of a monolayer of MB molecules over the surface of the RBP (molecular cloud of uniform thickness) 
and various pores and cracks characteristics of the RBP before adsorption were filled by RBP molecules, showing the adherent surface of the RBP adsorbent (Kumar et al., 2011; Bulut et al., 2006).

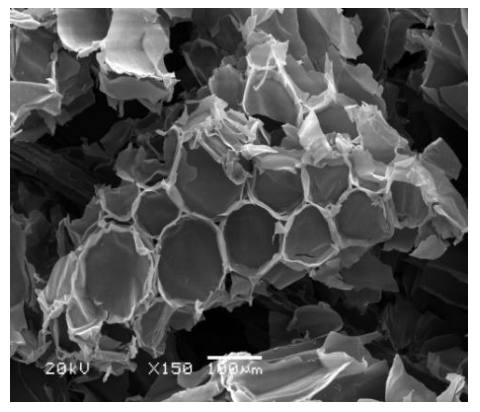

(a)

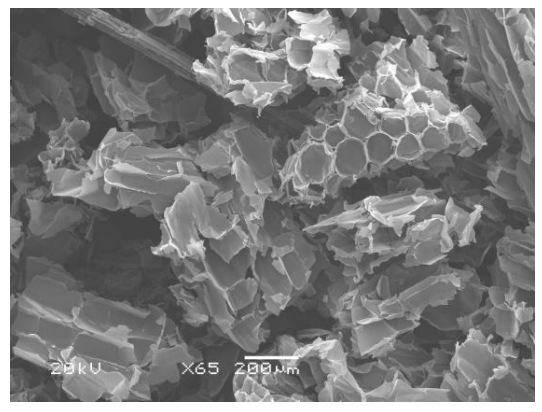

(b)

Figure 3. Raw Bagasse

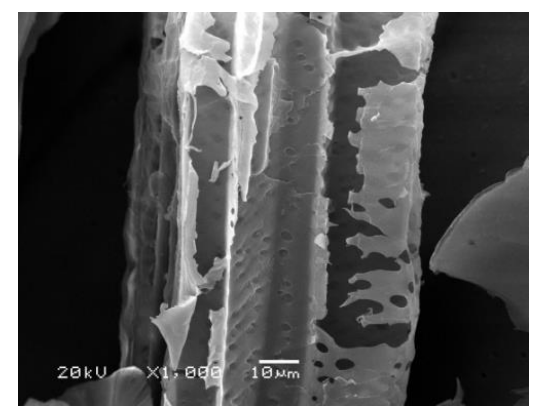

(a)

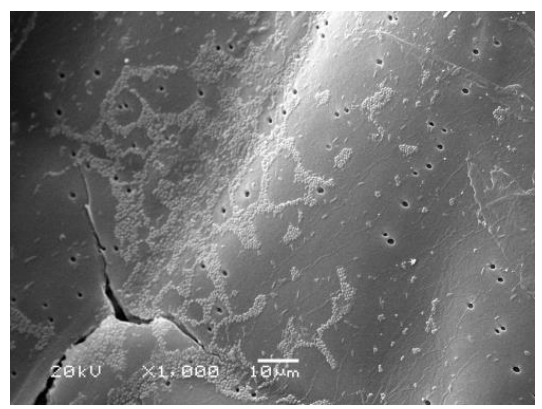

(b)

Figure 4. Adsorbed raw

SEM micrographs were used to determine the morphological changes in fiber structure and surface that occur due to the physical and chemical modification of sugar cane bagasse. Scanning electron image of the activated carbon which prepared from bagasse by physical treatment are shown in Fig. 5(a, b). The images show the cell structure of the bagasse with pits from the intercellular channels in the cell walls.

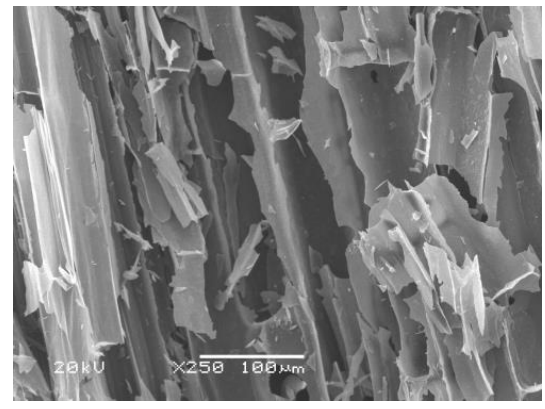

(a)

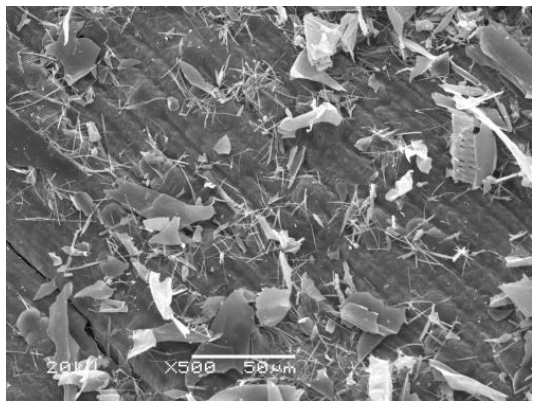

(b)

Figure 5. Physical

Micrograph shown in Fig. $6(a, b)$ reveals that a reduction in the size of the particles occurred after chemical modification of the RBP with $\mathrm{H}_{3} \mathrm{PO}_{4}$. It can be observed that the chemical modification process increased the 
number of pores and cracks on the fiber surface. Apparent reduction in the size of the particles can be noticed in Fig. 6 (c, d) after thermal treatment. The SEM images of the activated carbon show that the external surfaces are full of cavities and quite irregular. It appears to have numbers of macro pores and so there is a good possibility for dye to be adsorbed into pore.

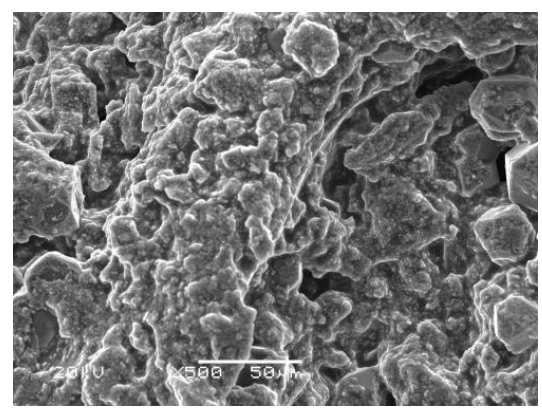

(a)

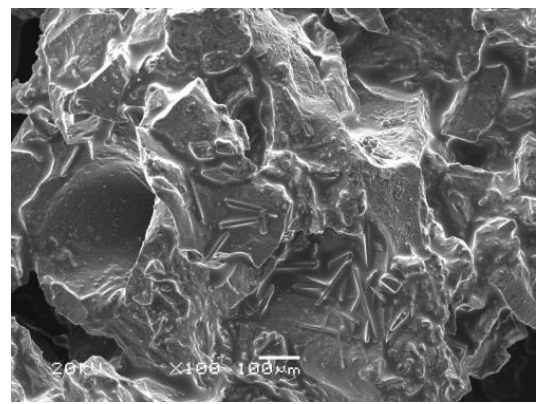

(c)

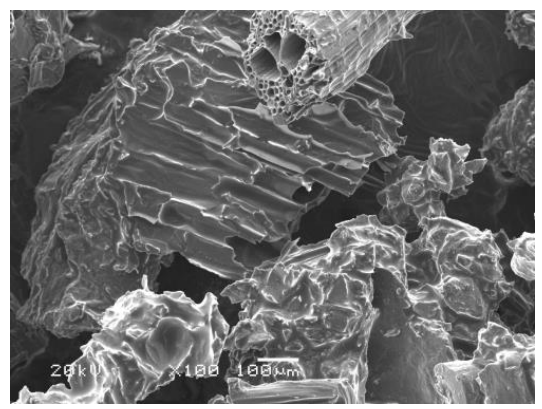

(b)

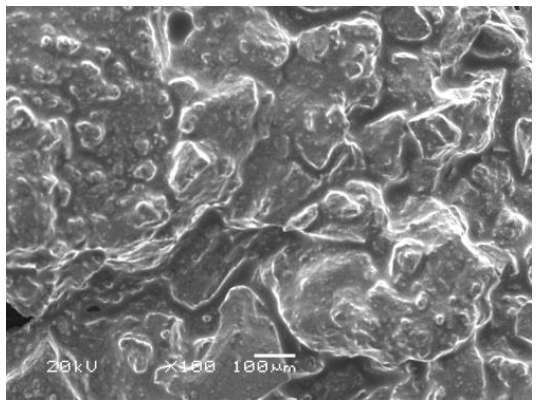

(d)

Figure 6. (a) $400{ }^{\circ} \mathrm{C}$, (b) $500{ }^{\circ} \mathrm{C}$, (c) $600{ }^{\circ} \mathrm{C}$, (d) $700{ }^{\circ} \mathrm{C}$

\subsection{Adsorption studies}

In the next section, the effect of initial dye concentration and contact time are discussed.

\subsubsection{Effects of Initial Dye Concentration and Contact Time}

The adsorption capacity of raw pith bagasse is studied. The results (Figure 7) indicated that the percentage of dye removal onto raw bagasse pith decreases with an increase in the initial dye concentration. The adsorption of $\mathrm{MB}$ dye was very rapid during the first $10 \mathrm{~min}$, and increased gradually during the second $20 \mathrm{~min}$. until reached equilibrium at $60 \mathrm{~min}$. The results showed that the uptake of $M B$ dye by raw bagasse pith depends on $\mathrm{MB}$ dose and contact time. This is because MB acts as the driving forces that increase the mass transfer of $\mathrm{MB}$ dye from aqueous solution onto the surface of raw bagasse pith. During the adsorption process, solutions with different initial concentrations possibly will reach equilibrium at different times. This may be due to the time required for the dye molecules to encounter the boundary layer effect, then diffuse to the surface of the adsorbent and finally diffuse to the porous structure of the adsorbent (Faust, 1983) Therefore, solutions with low initial concentration (10 ppm) reached equilibrium first at about $30 \mathrm{~min}$, while solutions with high initial concentration of $30 \mathrm{ppm}$ takes longer time and reached equilibrium at $60 \mathrm{~min}$. To ensure complete equilibrium of the data, adsorption samples were collected at $120 \mathrm{~min}$. This may be because the constant number of available sites in raw sugarcane bagasse is easily saturated by the increase of $M B$, which would lead to a decrease in the removal percentage of MB dye. Finally, it's clear that the amount of adsorption for dye removal is highly dependent on the initial dye concentration. The effect of initial dye concentration 
depends on the immediate relation between the concentration of the dye and the available sites on an adsorbent surface. In general, the percentage of dye removal decreases with an increase in the initial dye concentration, which may be due to the saturation of adsorption sites on the adsorbent surface (Senthilkumaar et al., 2005).

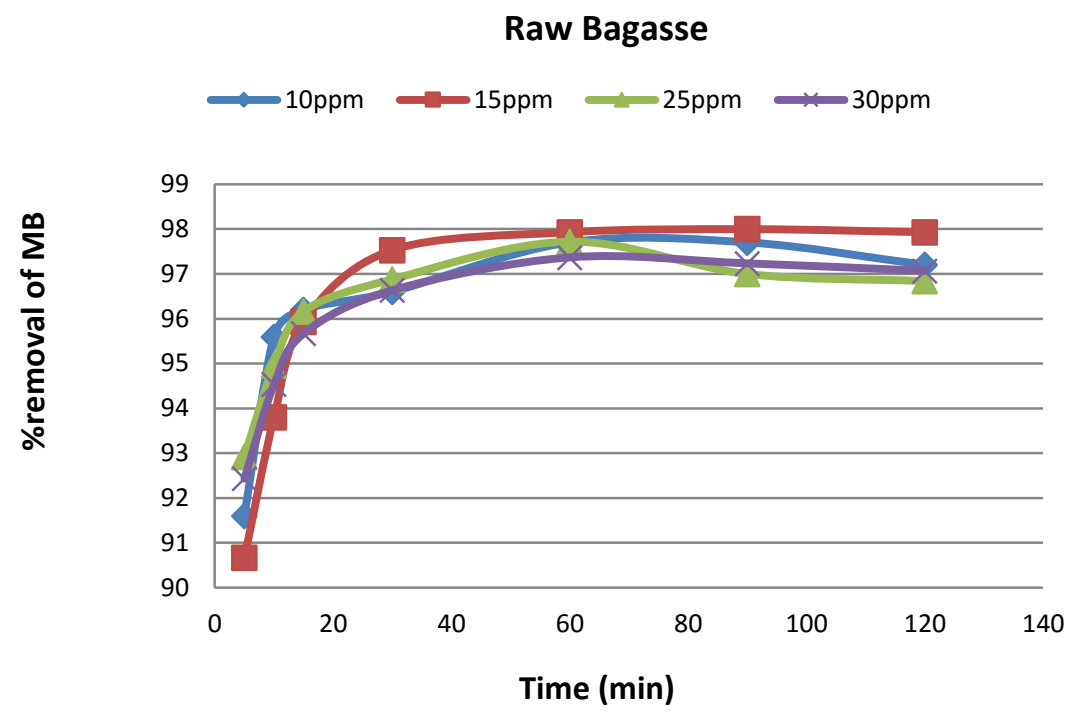

Figure 7. The variation of adsorption capacity with adsorption time at various initial MB concentrations at room temperature

\subsubsection{Effects of initial dye concentration and contact time on activated carbon physically prepared}

Effect of contact time on adsorption of cationic dye by activated carbon physically prepared is presented in Fig. 8.

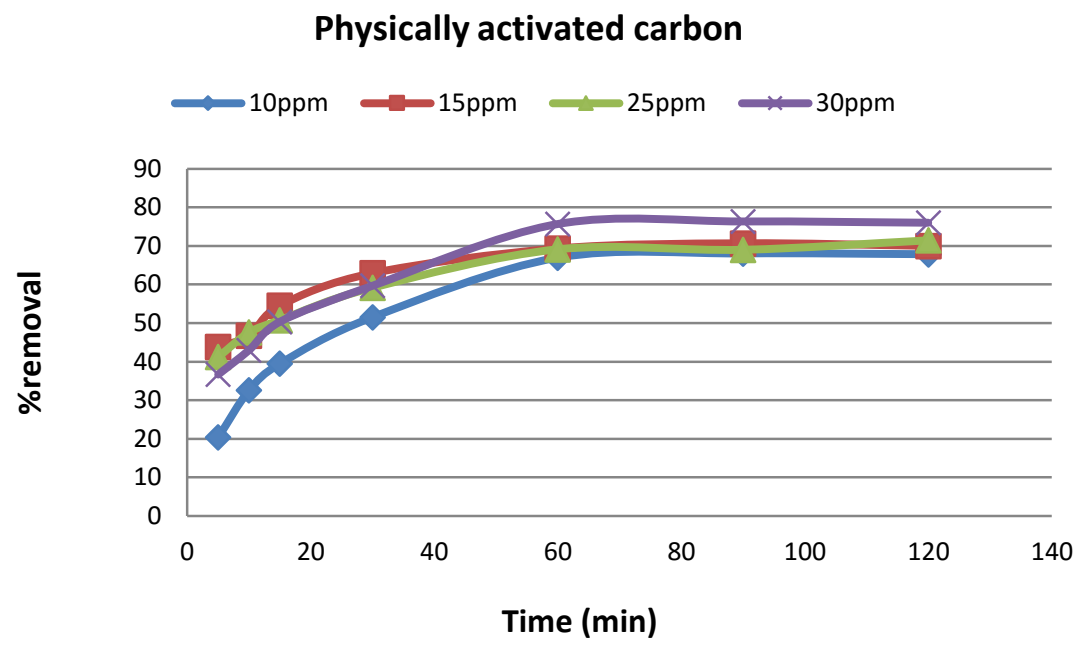

Figure 8. Effect of initial concentration and contact time on the adsorption of MB dye for activated carbon physically prepared 
It indicated that the contact time needed for MB solutions with initial concentrations of 10-30 ppm to reach equilibrium is $60 \mathrm{~min}$. However, the experimental data were measured for $2 \mathrm{~h}$ to make sure that full equilibrium was attained. As can be seen from Fig. 8, the amount of $\mathrm{MB}$ adsorbed onto the activated carbon increased with time and, at some point in time, it reached a constant value beyond which no more MB was further removed from the solution. At this point, the amount of the dye desorbing from the activated carbon was in a state of dynamic equilibrium with the amount of the dye being adsorbed onto the activated carbon. The amount of dye adsorbed at the equilibrium time reflects the maximum adsorption capacity of the adsorbent under those operating conditions. The adsorption capacity at the first five minutes increased from 20 to $40 \mathrm{mg} \mathrm{g}^{-1}$ with an increase in the initial dye concentrations from 10 to $30 \mathrm{ppm}$. Three consecutive mass transport steps are associated with the adsorption of solute from solution by porous adsorbent (AboulFetouh, 2010). First, the adsorbate migrates through the solution, i.e., film fusion, followed by solute movement from particle surface into interior site by pore diffusion and finally the adsorbate is adsorbed into the active sites at the interior of the adsorbent particle. This phenomenon takes relatively long contact time. A similar phenomenon was observed for the adsorption of methylene blue from aqueous solution on activated carbon and the equilibrium time was 60 min (Faust, 1983).

\subsubsection{Effect of contact time and initial dye concentration on dye removal of activated carbon chemically prepared}

The variations in dye adsorption per unit weight of $\mathrm{MB}$ with contact time at different initial concentrations of $10,15,25$ and $30 \mathrm{ppm}$ for the samples which chemically thermally prepared at $400-700{ }^{\circ} \mathrm{C}$ are presented in Figure 9.

\section{Chemically prepared}

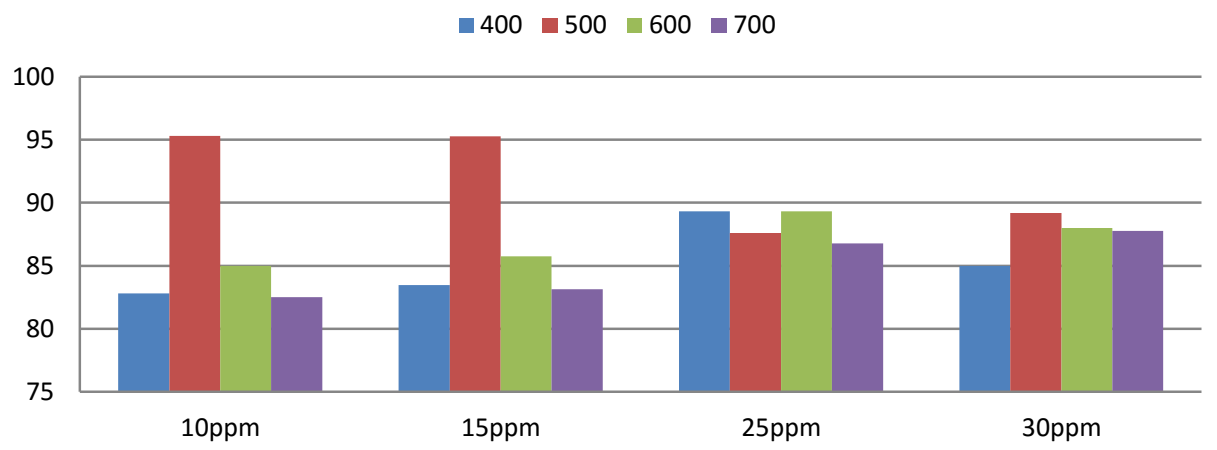

Figure 9. Effect of initial dye concentration and contact time on the adsorption of MB dye onto activated carbon chemically prepared at different temperatures

From the figure it can be observed that the rapid adsorption of dye takes place within the contact time of 5 minutes and there after adsorption process becomes slow. Further experiments were conducted with the contact time of 120 minutes duration. From the figure it can be observed that dye uptake increases with increase in dye concentration. Increase in dye uptake was due to the availability of higher amount of dye molecules in the solution. However, at the same time percent removal of dye was decreased. From the above observation, it is evident that for higher initial concentration of dye, the adsorption is very fast. The percentage removal of dye decreased with increasing initial dye concentration and takes longer time to reach equilibrium because of the fact that with increase in dye concentration, there will be increased competition for the active adsorption sites and the adsorption process will increasingly slow down. This explains the more adsorption time for higher concentration. In the process of dye adsorption, the dye molecules have to first 
encounter the boundary layer effect, then adsorb from the surface and, finally, they have to diffuse into the porous structure of the adsorbent. This phenomenon will take a relatively longer contact time. The initial rapid phase may also be due to the increased number of vacant sites available at the initial stage. By comparing the prepared samples at different temperatures, it's clear that the activated carbon prepared at $500{ }^{\circ} \mathrm{C}$ is the most effective one reach equilibrium after $60 \mathrm{~min}$.

\subsection{Isotherm study}

Modeling of experimental adsorption isotherm data is an essential way for predicting the mechanisms of adsorption. Several models have been studied to describe experimental data of adsorption isotherm three famous isotherm equations are the Langmuir, Freundlich and Temkin were employed for further interpretation of the obtained adsorption data.

\subsubsection{Langmuir isotherm model}

The basic assumption of Langmuir adsorption isotherm is based on:

1. The Langmuir isotherm has a theoretical justification.

2. Monolayer coverage of the adsorbate on the surface of adsorbent.

3. Adsorption is a reversible process.

4. The adsorbed molecules do not move on the surface of the adsorbent.

5. They can be lost back to the solution and the enthalpy of adsorption is the same for all molecules independently of how many have been adsorbed.

6. The Langmuir isotherm typically represents well data for single components.

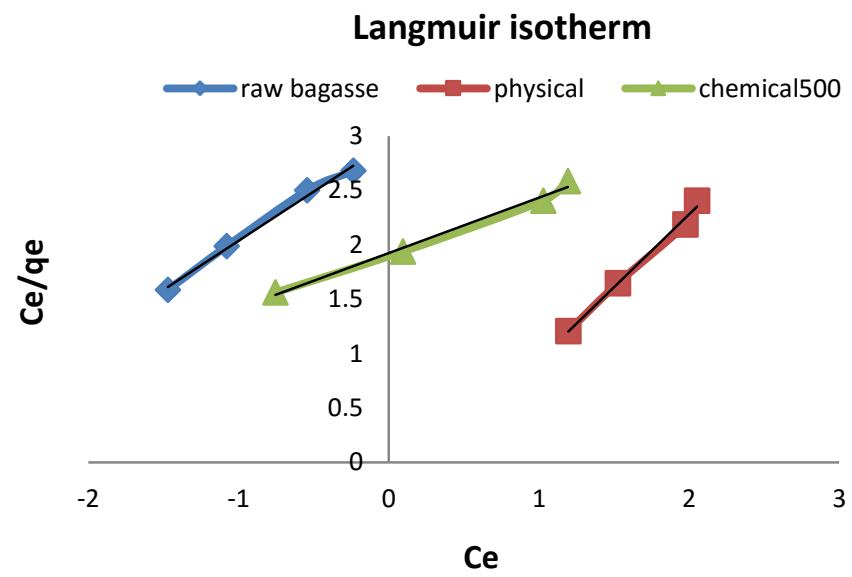

Figure 10. The linearization of adsorption isotherms for methylene blue ions adsorption by sugar bagasse at different condition

The equation that describes the Langmuir isotherm model is given in the following linear form:

$$
\frac{c_{e}}{q_{e}}=\frac{1}{q_{m} b}+\frac{c_{e}}{q_{m}}
$$

Where

$\mathrm{C}_{\mathrm{e}}$ is the final equilibrium concentration of adsorbate after adsorption has occurred, $\mathrm{mg} \mathrm{I}^{-1}$

$\mathrm{q}_{\mathrm{e}}$ is the adsorbent phase concentration after equilibrium, $\mathrm{mg}$ adsorbate/g adsorbent

$\mathrm{b}$ is the equilibrium adsorption constant which is related to the affinity of the bending sites, $\left(\mathrm{mg}^{-1}\right)$. 
$\mathrm{q}_{\mathrm{m}}$ is the maximum adsorption amount of adsorbate, $\left(\mathrm{mg} \mathrm{g}^{-1}\right)$ (Naiya, 2009).

Figure (10) shows that a linear plot of $C_{e} / q_{e}$ against $C_{e}$ given the slope $=q_{m}$ and intercept $=1 / b . q_{m}$. (Kumar, 2009).

\subsubsection{Freundlich isotherm model}

The equation that describes the Freundlich isotherm model is given in the following linear form:

$\operatorname{lnq} q_{e}=\frac{1}{n} \ln C_{e}+\operatorname{lnK} K_{f}$

where

$k_{f}$ is Freundlich constants that can be related to the adsorption capacity.

$\mathrm{n} \quad$ is Freundlich constants that can be related to the adsorption intensity

Figure (11) shows that a linear plot $\ln q_{\mathrm{e}}$ against $\ln C_{\mathrm{e}}$ given the slope $=1 / n$ and intercept $=\ln K_{\mathrm{f}}$. The linearization equations, the corresponding parameters and the correlation coefficients of Langmuir and Freundlich are given in Table (1).

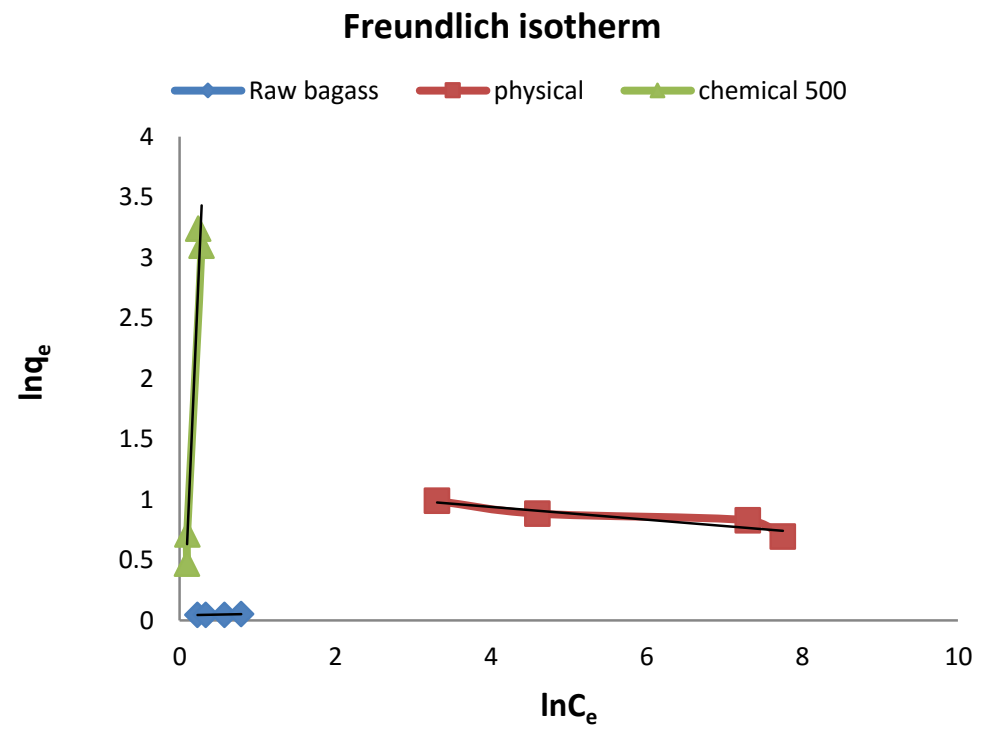

Figure 11. The linearization adsorption isotherms for methylene blue ions adsorption by sugar bagasse at different condition

\subsubsection{Temkin isotherm}

The Temkin isotherm equation assumes that the heat of adsorption of all the molecules in layer decreases linearly with coverage due to adsorbent-adsorbate interactions, and that the adsorption is characterized by a uniform distribution of the bonding energies, up to some maximum binding energy. (Oladoja, 2008).

The Temkin isotherm is given as:

$$
\mathrm{q}_{\mathrm{e}}=\mathrm{B}_{1} \ln \left(\mathrm{k}_{\mathrm{t}} \mathrm{C}_{\mathrm{e}}\right)
$$

where

$\mathrm{k}_{\mathrm{t}} \quad$ is the equilibrium binding constant corresponding to the maximum binding energy, $\left(\mathrm{dm}^{3} \mathrm{~mol}^{-1}\right)$. 
$B_{1} \quad$ is a constant related to the heat of adsorption.

A plot of $q_{e}$ versus $\ln C_{e}$ enables the determination of the isotherm constants $B_{1}$ and $k_{t}$ from the slope and the intercept, respectively.

Temkin isotherm equation contains a factor that explicitly takes into the account the adsorbing speciesadsorbent interactions (Srivastava, 2007).

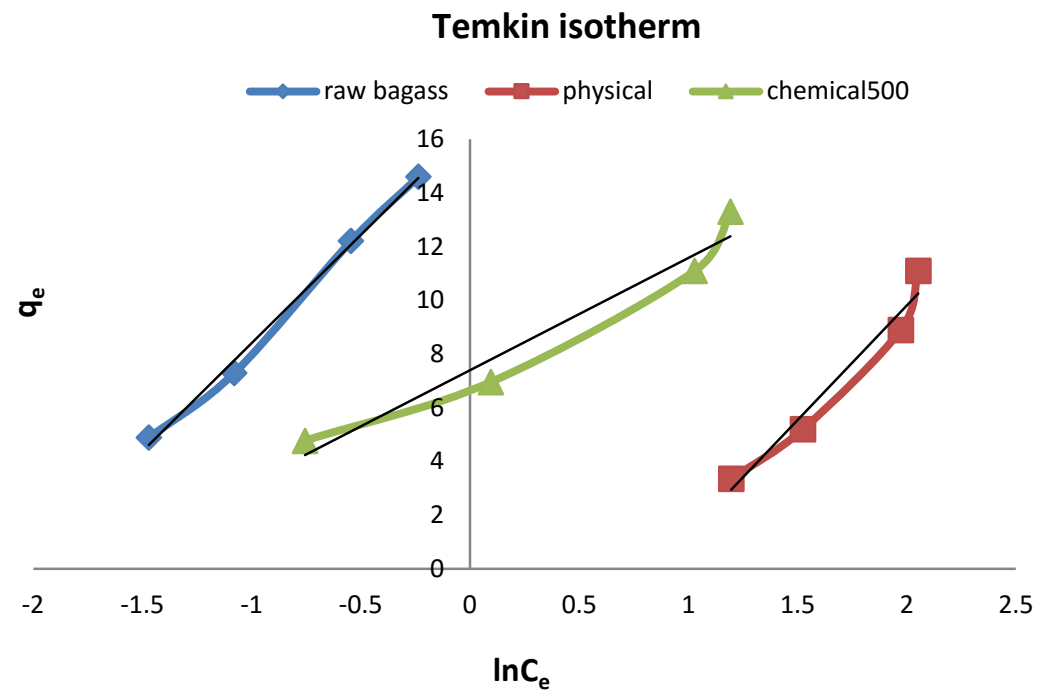

Figure 12. The linearization adsorption isotherms for methylene blue ions adsorption by sugar bagasse at different condition

Table (1) summarized the results of the isothermal constant comparison between raw, physical and chemical treated samples. For the correlation coefficients $\left(R^{2}\right)$, Langmuir model gave the highest value for all samples followed by Temkin model. But for Freundlich model the results seemed to be not fitted with this type of isothermal model. Also in Langmuir model, $R_{L}$ values is $<1$ this indicate that the type of isotherm is favorable.

Table 1. Isotherm parameters for removal of methylene blue by modified and unmodified sugarcane Bagasse

\begin{tabular}{|c|c|c|c|c|}
\hline \multirow{2}{*}{ Isotherm } & \multicolumn{4}{|c|}{ Parameters } \\
\hline & & Raw & Physical & Chemical \\
\hline \multirow{4}{*}{ Langmuir model } & $\mathrm{R}^{2}$ & 0.991 & 0.992 & 0.99 \\
\hline & $\mathrm{Q}_{0}$ & 1.1087 & 0.7457 & 1.9608 \\
\hline & $b$ & 0.3068 & -3.345 & 0.26507 \\
\hline & $\mathrm{R}_{\mathrm{L}}$ & 0.115 & -0.0121 & 0.13118 \\
\hline \multirow{3}{*}{ Freundlich model } & $\mathrm{R}^{2}$ & 0.716 & 0.844 & 0.951 \\
\hline & $N_{f}$ & 83.33 & -19.23 & 0.065 \\
\hline & $K_{f}$ & -3.1466 & 1.152 & -0.866 \\
\hline \multirow{3}{*}{ Temkin model } & $\mathrm{R}^{2}$ & 0.994 & 0.955 & 0.951 \\
\hline & $A$ & 0.7128 & -0.865 & 1.769 \\
\hline & $B$ & 8.070 & 8.548 & 9.179 \\
\hline
\end{tabular}




\section{Conclusion}

It is observed that activated carbon prepared from raw bagasse pith, after only one chemical modification step is going to be efficient for removing $\mathrm{MB}$ from aqueous solutions by adsorption. Equilibrium adsorption times were found to be $1 \mathrm{~h}$ for MB. The adsorption isotherm equations like Freundlich, Langmuir and Temkin were applied to check the feasibility of adsorption process. On the basis of correlation coefficient values it is concluded that the mechanism of adsorption of dyes in the raw, physical and chemical treated sugarcane bagasse follows both Langmuir and Temkin adsorption isotherms. Waste treatment by adsorption using low cost adsorbent is a demanding area as it has double benefits i.e. water treatment and waste management.

\section{References}

Aboul-Fetouh M.S., Elmorsi T.M., El-Kady J.M. and El-Adawi H.A. (2010), Water Hyacinth Stems a Potential Natural Adsorbent for the Adsorption of Acid Green 20 Dye, Environmental Science: An Indian Journal, 5(4), 257-266.

Annadurai G., Chellapandian M. and Krishnan M.R.V. (1999), Adsorption of Reactive Dye on Chitin, Environmental Monitoring and Assessment, 59(1), 111-119.

Annadurai G., Juang S.R. and Lee J.D. (2002), Use of Cellulose-Based Wastes for Adsorption of Dyes from Aqueous Solutions, Journal of Hazardous Materials, 92(3), 263-274.

Babel S. and Kurniawan T.A. (2003), Low-cost adsorbents for heavy metals uptake from contaminated water: a review, Journal of Hazardous Materials, 97(1), 219-243.

Billy G.T.H., Abdul Latif P. and Yap T.Y.H. (2013), Physical Preparation of Activated Carbon from Sugarcane Bagasse and Corn Husk and Its Physical and Chemical Characteristics, International Journal of Engineering Research and Science and Technology, 2(3), 1-14.

Bulut Y. and Aydin H.A. (2006), Kinetics and thermodynamics study of methylene blue adsorption on wheat shells. Desalination, 194(1), 259-67.

Crini G. (2006), Non-conventional low-cost adsorbents for dye removal: a review, Bioresource Technology, 97, 1061-1085.

Crini G. (2008), Kinetic and equilibrium studies on the removal of cationic dyes from aqueous solution by adsorption onto a cyclodextrin polymer, Dyes Pigments, 77, 415-426.

Devaprasath P.M., Solomon J.S. and Thomas B.V. (2007), Removal of $\mathrm{Cr}(\mathrm{VI})$ from aqueous solution using natural plant material, J. Appl. Sci. Environ. Sanit., 2, 77-83.

El-Geundi M.S. (1991), Color Removal from textiles effluent by Adsorption Techniques, Water Research, 25(3), 271-273.

Faust D.S. and Aly M.O., Chemistry of Wastewater Treatment, Butterworths, Boston, 1983.

Forgacs E., Cserhati T. and Oros G. (2004), Removal of synthetic dyes from wastewaters: a review, Environment International, 30, 953-971.

Foo K.Y. and Hameed B.H. (2011) b, Preparation and characterization of activated carbon from pistachio nut shells via microwave-induced chemical activation, Biomass. Bioenergy, 35, 3257-3261.

Gong R., Sun Y., Chen J., Liu H. and Yang C. (2005), Effect of chemical modification on dye adsorption capacity of peanut hull, Dyes Pigments, 67, 175-181.

Gusmãoa K., Gurgelb L., Meloa T. and Gila L. (2012), Application of succinylated sugarcane bagasse as adsorbent to remove methylene, Dyes and Pigments, 92, 967-974.

Kaur S., Rani S. and Mahajan R.K. (2013), Adsorptive removal of dye crystal violet onto low-cost carbon produced from Eichhornia plant: kinetic, equilibrium, and thermodynamic studies, Desalination and Water Treatment, 53(2), 543-556.

Kumar U. (2009), Sorption of Cadmium from Aqueous Solution by Sodium Hydroxide Pretreated Rice Husk. Proceedings of International Conference on Energy and Environment, March 19-21. 
Kumar R. and Ahmad R. (2011), Biosorption of hazardous crystal violet dye from aqueous Solution onto treated ginger waste (TGW), Desalination, 265, 112-118.

Lazaridis N.K., Darapantsios T.D. and Georgantas D. (2003), Kinetic analysis for the removal of a reactive dye from aqueous solution onto hydrotalcite by adsorption, Water Research, 37, 3023- 3033.

Liou T.-H. (2010), Development of mesoporous structure and high adsorption capacity of biomass-based activated carbon by phosphoric acid and zinc chloride activation, Chemical Engineering Journal, 158, $129-142$.

Litza H., Jimenez V., Pavlick A. and Mendez J. (2013), Chemical characterization of raw and treated agave bagasse and its potential as adsorbent of metal cations from water, Industrial Crops and Products, 43, 200- 206.

Miah M.Y., Volchek K., Kuang W. and Tezel F.H. (2010), Kinetic and Equilibrium Studies of Cesium Adsorption on Ceiling Tiles from Aqueous Solutions, Journal of Hazardous Materials, 183(1-3), 712-717.

Miretsky P. and Cirelli F.A. (2010), $\mathrm{Cr}(\mathrm{VI})$ and $\mathrm{Cr}$ (III) removal from aqueous solution by raw and modified lignocellulosic materials: a review, Journal of Hazardous Materials, 180, 1-19.

Moussavi G. and Khosrav R. (2011), The removal of cationic dyes from aqueous solutions by onto pistachio hull waste, Chemical engineering research and design, 89, 2182-2189.

Naiya T.K., Chowdhury P., Bhattacharya A.K. and Das S.K. (2009), Saw dust and neem bark as low-cost natural biosorbent for adsorptive removal of $\mathrm{Zn}(\mathrm{II})$ and $\mathrm{Cd}(\mathrm{II})$ ions from aqueous solutions, Chemical Engineering Journal, 148, 68-79.

Oladoja N.A., Aboluwoye C.O. and Oladimeji Y.B. (2008), Kinetics and Isotherm Studies on Methylene Blue Adsorption onto Ground Palm Kernel Coat, Turkish Journal of Engineering Environmental Science, 32, 303-312.

Puziy A.M., Poddubnaya O.I., Alonso M.A., Garcia S.F. and Tascon J.M.D. (2005), Surface chemistry of phosphoruscontaining carbons of lignocellulosic origin, Carbon, 43, 2857-2868.

Rachakornkij M., Ruangchuaya S. and Teachakulwiroj S. (2004), Removal of reactive dyes from aqueous solution using bagasse fly ash, Environmental \& Hazardous Management, 26, 13-24.

Ramakrishna K.R. and Viraraghavan T. (1997), Dye removal using low cost adsorbents, Water Science and Technology, 36(2), 189-96.

Salleh M.A.M., Mahmoud D.K., Abdul Karim W.A.W. and Idris A. (2011), Cationic and anionic dye adsorption by agricultural solid wastes: a comprehensive review, Desalination, 280(1), 1-13.

Senthilkumaar S., Varadarajan P.R., Porkodi K. and Subbhuraam C.V. (2005), Adsorption of methylene blue onto jute fiber carbon: kinetics and equilibrium studies, Journal of Colloid and Interface Science, 284(1), 78-82.

Srivastava V.C., Malla I.D. and Mishraa I.M. (2007), Adsorption thermodynamics and isosteric heat of adsorption of toxic metal ions onto bagasse fly ash (BFA) and rice husk ash (RHA), Chemical Engineering Journal, 132, $267-278$.

Tseng R.L. (2002), Characterization and use of activated carbons prepared from bagasse for liquid-phase adsorption, Colloids and Surfaces A: Physicochemical and Engineering Aspects, 201, 191-199.

Wu F-C. and Tseng R-L. (2008), High adsorption capacity NaOH-activated carbon for dye removal from aqueous solution, Journal of Hazardous Materials, 152, 1256-1267.

Zhao X., Urano K. and Ogasawara, S. (1989), Adsorption of Polyethylene Glycol from Aqueous Solution on MontRillonite Clays, Colloid and Polymer Science, 267(10), 899-906.

Zollinger H. (1987): Colour Chemistry-Synthesis, Properties and Application of Organic Dyes and Pigments, VCH, NewYork. 